Opening address at the 2014 SAERA conference

\title{
Angels in the wind: future directions for educational research
}

\section{Michael Samuel}

(Chair of the Local Organizing Committee)

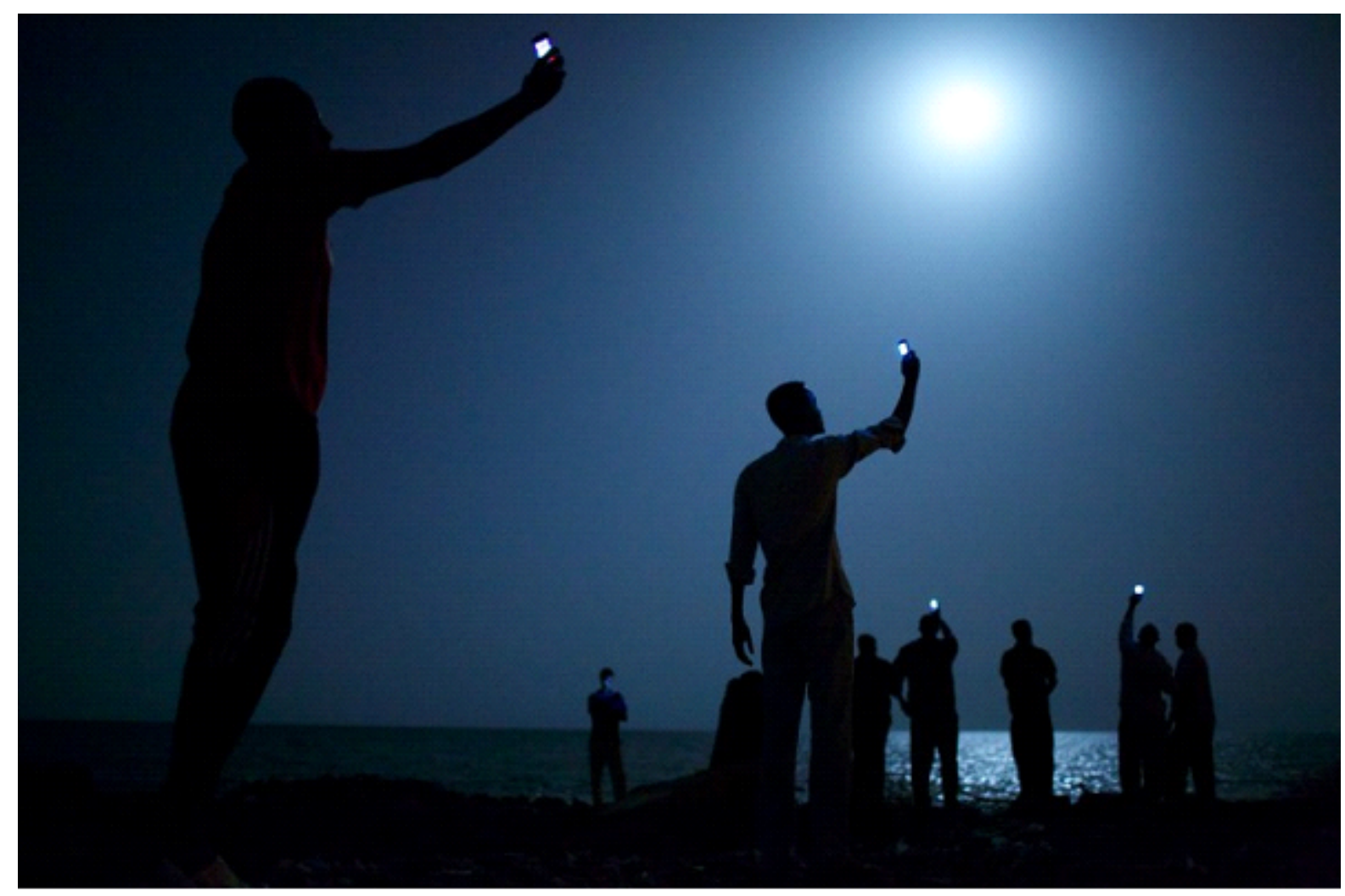

Stanmeyer, John 2013. 'Sign', National Geographic

An annual prestigious event in the calendar of professional press photographers, photojournalists and documentary photographers is the World Press Photo Award. This event in 2013 was co-ordinated by the World Press Photo Office in Amsterdam and attracted 98671 submitted images by 5754 photographers from 132 countries

(http://www.worldpressphoto.org/awards/2014). The independent jury of judges for the 57th annual event selected this photograph above by John Stanmeyer, a USA journalist of the National Geographic as the wining photographic image in the category 'Contemporary issues'. Stanmeyer had 
simply titled his image 'Sign'. It was accompanied by the explanation of his attempt to capture the challenges facing the would-be migrants alongside the coast of Djibouti (North East Africa). These haunting 'army of shadows' (RADAR Worldwide, 2014) reflects groups of prospective migrants who are aiming to make the journey to better life opportunities by crossing over the oceans into the Middle East or beginning the journey into Europe. Coming from the surrounding countries of Somalia, Ethiopia and Eritrea, this image depicts a new kind of Exodus facing the participants who stand alongside the shores searching for signals on the cellphones, aiming to connect a last call to family and friends back home, aiming to connect with the traffickers who had promised a safe passage (legal or not) into the lands of prospects. Their sense of hopeless desperation is not the focus of the image itself. The picture captures instead glimmers of light as cellphone screens dot the darkness. The photograph is one of hope, the search for international connection, the need for making connections with others. An awarding judge, Jillian Edelstein (UK/South Africa) commented on the photo:

It's a photo that is connected to so many other stories - it opens up discussions about technology, globalisation, migration, poverty, desperation, alienation, humanity. It's a very sophisticated, powerfully nuanced image. It is so subtly done, so poetic, yet instilled with meaning, conveying issues of great gravity and concern in the world today. (my emphasis added) http://www.worldpressphoto.org/awards/2014

We all know that the journey of migration for some has been repeated several times over in many parts of the world, some with fatal consequences, when migrants are shipwrecked, stranded, abandoned or exploited by those who promise a better life opportunity. We know too that some migrants end up in the degradation of barricaded immigrant camps, sometimes tortured and humiliated by the authorities that police the borders of national geographies. Many are simply deported back to the countries of origin. Even when they enter the foreign lands, we know they become victims of xenophobia as nationalistic overtures interpret their conduct and agendas. We know also the resilience of many who repeat their previous failed journey several times over, searching, searching for means to escape their poverty, searching for economic or health security, searching for better qualitative education systems; escaping the ravages of natural, economic and political disorders. Migration is as old as history, and border crossings have always been points of contestation. In his classical novel 'Waiting for the Barbarians', J.M. Coetzee heightened our awareness of how border control camps become symbolic of our internal rather than external constructions of threat. Borders 
become the very spaces where our constructed certainties become questioned, become possibilities for thinking anew.

Susan Linfield, the USA judge commented on the selection process of finding the award winning image as follows:
What we're looking for in the winning image is the same quality you would look for in a great film or in literature - the impression that it exists on more than one level, that it makes you think about things you haven't thought about. You begin to explore the layers not only of what's there, but of what isn't there. So many pictures of migrants show them as bedraggled and pathetic. . .but this photo is not so much romantic, as dignified. (my emphasis added).

I believe that today as we begin this historical agenda of the second South African Education Research Association (SAERA) 2014 conference we are also on a journey of pilgrimage, a search for new directions, new beginnings. In this search we are connected into the debates and contestations around our pasts, our heritages, technology, globalisation, migration, poverty, desperation, alienation, and humanity. We know that there are many images to be presented and debated in this conference and that each image is capable of being interpreted on more than one level. Like the image of John Stanmeyer's 'Sign', the conference is a space to engage things that we have not yet thought about; to rethink how we police the boundaries of our own thoughts, habits, rituals and routines. This is a conference about layers: layers of people, positionalities, personalities, paradigms, organisations, spaces and methodologies. We must always be conscious not only of what people say to us, but also what are the silences: what is not being said. I encourage us all to focus on what or who is not heard in our debates, our deliberations. I ask you to pay attention to which participants and their foci are given supremacy over others. Are we creating sufficient spaces for a confluence of voices in the wind?

My belief is that South African education research has to move beyond simply the 'bedraggled and pathetic'. Instead we should be searching for a 'dignified form' of educational research activity that will harness the wonderful potential we already possess. Perhaps this is a time to put aside our obsession with the policy euphoria we noted in our early days of liberation in a new South Africa? Have we seen enough of the celebration of oppression and deficiency which dominate our fixations? Will dwelling on the failures of the system be adequate to move towards new directions? One is permitted to question whether a focus on success could elevate us out of the morass of 
deficiency, failure or toxicity? What are complimentary spaces within which we can activate an alternative society, an alternative quality education system? I wonder whether this is quest for a dignified pedagogy which will challenge those who wallow in their complaints of systemic failure of education. Can we move away from a 'pedagogy of disillusion' to 'pedagogy of hope, possibility, creativity, meaningfulness'? The many papers activated in this conference aim to share with you the possibilities and limitations for such opportunities.

For example, some of the papers in this conference ask the following questions:

- $\quad$ Are there alternative models of delivery, modes of recognition of self and others, recognition of the small glimmers of possibilities?

- How do we work beyond romantic protection of our small enclaves of excellence? How do we expand to become more than simply the consequences of the past? Are we slaves to our biographical (racialised) (contextualised) (esssentialised) histories?

The papers in this conference should be exploring some of the major international challenges of alternative forms of education delivery using new technologies (for example: Massive Online Open Communication-MOOC's) as networks of teaching and learning which constitute a major possibility for thinking anew the classroom as a learning/teaching space. Can these new technologies usher in new possibilities or will they further divide the haves and the have-nots? Are these new technologies indeed new forms of equitable access to education?

What possibilities can "flipping our classroom" pedagogy bring (Tucker, 2012)? Can the classroom/lecture halls become spaces for consolidating and negotiating learning that happens outside of the classroom, in the home, through the media and the internet/electronic highways? Some may argue that the essence of education has always being on mediating the "outside world" with the "world of school"? So what is new? How do we move the central focus of the debate around pedagogy not to be about teacher- or learnercentered interaction, but instead on creating opportunities for learningcentred engagement? 


\section{SAERA 2014: A feast of inputs}

This SAERA 2014 conference offers a range of opportunities in activating an extension of ourselves. These include challenges from the keynote speakers such as Prof. Elizabeth Henning (Centre for Education Practice Research, University of Johannesburg) who asks 'whereto with the science and the social justice of child assessment in South African schools?' In this presentation we will engage with the effects of assessment regimes within the new performativity cultures characterising our 'modern education terrain'. Our visitor from the World Education Research Association, Dr. Felice Levine (President-elect of the World Education Research Association (WERA) poses for us as South Africans questions on 'the international footprint of Education Research - A 21st Century Work in Progress'. The future links between SAERA and WERA are part of this discussion. Our plenary panel members (Day Three) pose their interpretations of critical issues in South African education research: searching for a relationship between educational research and sustainable learning environment (Prof. Sechaba Mahlomaholo (UFS); for systemic evidence in the choices for our South African classrooms (Prof. Servaas van den Berg [SU]). We are further challenged that boundaries of education research should not be confined within the classrooms of school (general or further education). Instead, we should look towards the relationship between post-school and the Labour Market (Prof. Peliwe Lolwana: Director of the Centre for Research in Education and Labour Markets (REAL). The shape, form and direction of post-school education and new planned legislation are repeated mantras across some papers of this conference.

Other highlights of the conference include $+/-175$ papers to be presented, the launch of the conference proceedings (OUP), 4 book launches and a pre-conference training for postgraduate supervisors and students. The conference is an opportunity to generate new forms of engagement in educational conferences such as the commencement of 'Conversation Circles'. Another innovation is the presentation of Photographic/Artistic Exhibits (alongside poster presentations) as a representational form of delivery at a conference. The conference will also be an opportunity to start dialogue about the formation of Special Interest Groups. We will be engaging in an opportunity to question what implications there are for exploring the Mandela Legacy in our educational research. There are approximately 5 editors of educational journals present in the conference and there will be an 
opportunity for you to meet them. All these innovations are listed in detail in the Programme and Abstract booklet.

The closing Annual General Meeting (AGM) of the Kenton conference will occur during the course of this conference; the second AGM meeting of the new SAERA organisation will also take place. We have created opportunities for various associations/organisations to set up bilateral discussions with the new SAERA organisation, the world body (WERA) representatives about the current and future identity of their present organisations. There will be opportunities for social activities: browsing in bookstores, cocktail evenings, a conference dinner and closing with a bus tour of Durban, its cultural heritages and spaces. These are all opportunities for imagining ourselves anew - a look into the future.

\section{RE-Search Association}

So what are some of the questions which are an emergent new research association could be asking? I list my personal preferences which, I am sure, resonate with many others:

- What are some of the stumbling blocks to the realisation of the goals of educational research?

- If we argue that the trajectory to new forms of education research is NOT necessarily about the lack of finances to do the research, what is driving the nature, shape, form, type of education research in SA currently:

- increasing commodification of the research agenda process?

- increasing push to deliver simultaneously training, support, development, education, critique and research ('work intensification') within Schools, Faculties of Education or organisations of education research inside, alongside or outside governmental structures?

- fundamental shifts to manage the university/ research systems to be 'business orientated' producers of research? 
Increasingly reports of the dissatisfaction of new performativity identities being foisted onto the notion ('identity') of the university as a system dominates the critique of education research. We seem to be ushering new fashionable fads to provide semblances of 'better quality education' whilst not deeply attending to matters of what are the essences of relevant, adequate and meaningful teaching and learning. Some would argue that the very identities of institutions of teaching and learning are being derailed. For example, the notion of the university as a deliberative space of 'organised anarchy' (Teferra, 2014) is being mutated to reflect corporate-like structures. Models imported from the business world are imposed on a university structure which thrives precisely because of its 'systemic chaos'. These 'traditional' models of universities are increasingly being jettisoned to make way for an insidious accountability regime which demands tangible 'return on investment' (a logic from the market) (Torres, 2011). More attention to university teachers as siloed units of productivity are the flavour of managers of higher education who have embraced the 'market' logic. This has a tendency to subvert intellectuals into disciplinary enclaves, thus potentially thwarting the possibility of blurred boundaries thinking across the disciplines (Maistry, 2014). Output rather than innovation tends to dominate in such 'regimes of truth' (Foucault, 1979).

\section{Education as a social discipline}

In this section I would like to emphasise Frederico Matos' (2013) commentary on the status of education research within the broader terrain of university research. He argues that we do not sufficiently acknowledge the differences between how research is produced at the level of PhDs amongst the social sciences and within the natural sciences. Given the dominance of the Natural Sciences as an income generator from outside financers ('third stream income'), the elevation of its models is positioned as the target towards which all higher education should aspire. He presents the following table outlining the major differences between the Social Sciences and Natural Sciences. If we locate Education and Education Research within the social sciences we can see how there are some emergent threats to the future of education research when we adopt too boldly/ blindly the Natural Science paradigms. 
Table 1: Diferences between PhDs in social science and in the
natural sciences (Matos, 2013, p.631)

\section{PhD in the Social Sciences}

\begin{tabular}{ll}
$\begin{array}{l}\text { Scope of the } \\
\text { thesis }\end{array}$ & $\begin{array}{l}\text { Student responsible for whole } \\
\text { research project }\end{array}$ \\
\hline Topic of the thesis & Student's own \\
\hline Results & Only positive results accepted \\
\hline $\begin{array}{l}\text { Proximity to } \\
\text { supervisor }\end{array}$ & Meeting by arrangement \\
\hline $\begin{array}{l}\text { Location } \\
\text { Proximity to other }\end{array}$ & $\begin{array}{l}\text { Student rarely has own space } \\
\text { provided by department/university. } \\
\text { researchers }\end{array}$ \\
\hline Funding & $\begin{array}{l}\text { Student has to apply individually for } \\
\text { funding }\end{array}$ \\
\hline
\end{tabular}

\section{PhD in Naural Sciences}

Student responsible for a part of a wider research project

Part of a wider research project and selected/assigned by the supervisor/principal investigator

Negative results accepted

Constant presence of supervisor

In the lab

Close to other researchers in same lab

Attributed to student as part of the overall funding for supervisor's project

\section{Possible threats to education research}

Matos (2013) predicts what would happen if we too categorically accept the Natural Sciences models and adopt the business model within (social science) education research. We are likely to see:

- $\quad$ a shift in the kinds of students we (social science supervisors) select to support in PhD studies: (we would tend to choose only those we know will succeed in minimum time);

- $\quad$ a restriction of the choice of the topics we choose that can be completed in 'allotted time': (simple rather than complex studies will be preferred);

- the possible replication of research studies that maintain quantity outputs, offering little but an 'expansionist' contribution to the body of knowledge or the field of study: (convenient research would aim to push back boundaries only of a contextual nature. This would entail merely 
filling in a 'blank spot' of research within contexts not yet not investigated. This may have the effect of fostering an importation of models which may homgenise insight in education research. This challenges the possibility for deep theoretical or conceptual explorations in research. The latter Gough calls "blind spot" research: research asking what kinds of questions we need to ask about our research agendas or the field) (Gough, 1998).

- a potential dumbing down of the $\mathrm{PhD}$ to generate the "credentialed output' in minimum time: (fostering a product chasing mentality);

Unfortunately these choices will then become the hallmarks of what will be regarded as 'productive academics'.

\section{Conference as dialogue}

Therefore I believe that this SAERA 2014 conference and in its future iterations are an ideal opportunity to confer, to ask the following questions:

- How do we borrow; exchange; redirect our heritages from the past education research practices?

- How are we making selections of the kinds of paradigmatic positions in our research? What types of questions will we be asking in our research agenda: expedient, convenient or troublesome questions?

- How do we borrow our models (theoretically/methodologically) in term of what is considered valuable or not for educational research here in our situated contexts?

- Whose models do we inherit? What could we discard or reformulate?

- Can we dream ourselves anew? 


\section{Closing/opening thoughts}

I close with the feminist researchers' reminder: 'History is an angel being blown backwards into the future' (Lather and Smithies, 1997, p.54).

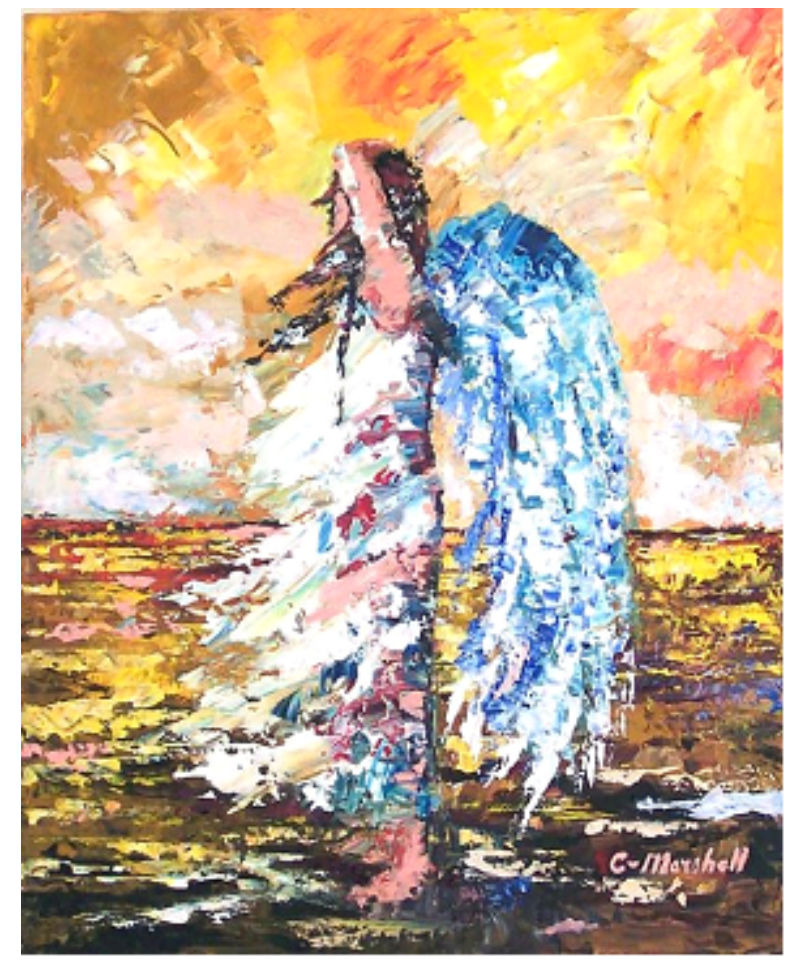

(http://images.fineartamerica.com/images-medium/angel-in-the-wind-claude-marshall.jpg)

Are we prepared to be blown backwards into the future? Are we making choices that will avoid being buffeted in the wind? Are we the angels of the wind?

We wish all a productive thought-provoking SAERA 2014 conference. Welcome to Durban. 


\section{References}

Foucault, M. 1979. Discipline and punish: birth of prisons. New York, Vintage.

Gough, N. 1998. Narrative and educational inquiry. In Mousley, J., Gough, N., Robson, M.and Colquhoun, D. (Eds), Horizons, images and experiences: the research stories collection. Geelong: Deakin University, pp.118-127.

Lather, P.A. and Smithies, C.S. 1997. Troubling the angels. Women living with HIV/AIDS. Boulder, CO: Westview Press.

Marshall, C. 2014.

http://images.fineartamerica.com/images-medium/angel-in-the-wind-claude-m arshall.jpg

Maistry, S. 2014. Education for economic growth: a neoliberal fallacy in South Africa. Alternations (in press).

Matos, F. 2013. PhD and the manager's dream: professionalising the students, the degree and the supervisors? Journal of Higher Education Policy and Management, 35(6): pp.626-638.

Teferra, D. 2014. Organised anarchy - the enduring university paradigm. University World News - The Global edition. 20 July 2014.

Torres, C. 2011. 'Public universities and neoliberal common sense: seven iconoclastic theses.' International Studies in Sociology of Education, 21(3): pp.177-197.

Tucker, B, 2012. 'The flipped classroom'. Online instruction at home frees classtime for learning. Education Next. Winter 2012.Volume 12/No.1. http://educationnext.org/the-flipped-classroom/ Retrieved 11 August 2014.

RADAR Worldwide Magazine 2014. The rainbow nation: an unfulfilled dream. Worldwide, April-May 2014, p.6.

World Press Photo Awards. http://www.worldpressphoto.org/awards/2014 Retrieved 20 July 2014. 
Flipping the classroom images.

http://www.bing.com/images/search?q=flipping+the+classroom\&id=6AC099 ECD39CF293BA0C24CFDE4D1B8C23C9A4E4\&FORM=IQFRBA\#view $=\mathrm{d}$ etail\&id=6AC099ECD39CF293BA0C24CFDE4D1B8C23C9A4E4\&selected $\underline{\text { Index }=0}$

Michael Samuel

School of Education

University of KwaZulu-Natal

$\underline{\text { Samuelm@ukzn.ac.za }}$ 